\title{
ANALISA DAN PENGEMBANGAN SISTEM INFORMASI JUMLAH MASYARAKAT PENGANGGUR DINAS TENAGA KERJA DAN TRANSMIGRASI
}

\author{
Fabianus Yayan, Taufan Rifai, Hidayatulah Himawan \\ Prodi Teknik Informatika UPN "Veteran" Yogyakarta \\ Jl. Babarsari 2 Tambakbayan 55281 Telp (0274) 485323 \\ email: if.iwan@gmail.com
}

\begin{abstract}
Advances in science and technology is growing. Almos every agency of government has felt the impact of technology advances. In order to meet the performance and mobility of the employees would not want to participate and take advantage of the technologycal sophistication. Advances in technology, innovation and efficiency continue to be done to support the performance of employees in a varity ways, including viewing and analyzing th enumber of people unemployed in a region. So this study is more on providing information and analysis on the spred factor of unemployment in a region.

Keywords : information systems, analysis, mapping of

Kemajuan ilmu pengetahuan dan teknologi semakin berkembang. Hampir disetiap instansi pemerintah telah merasakan dampak dari kemajuan teknologi . Demi memenuhi kinerja dan mobilitas para pegawai mau tidak mau turut serta memanfaatkan kecanggihan teknologi tersebut. Kemajuan teknologi, inovasi dan efesiensi terus dilakukan untuk menunjang kinerja para pegawai dalam melakukan berbagai hal, termasuk melihat dan menganalisa jumlah masyarakat penganggur di suatu wilayah. Sehingga penelitian ini lebih kepada pemberian informasi dan analisa terhadap faktor penyebaran pengangguran di suatu wilayah
\end{abstract}

Kata kunci : sistem informasi, analisa, pemetaan wilayah

\section{PENDAHULUAN}

Dewasa ini kemajuan ilmu pengetahuan dan teknologi semakin berkembang. Hampir disetiap instansi pemerintah telah merasakan dampak dari kemajuan teknologi. Demi memenuhi kinerja dan mobilitas para pegawai mau tidak mau pemerintah turut serta memanfaatkan kecanggihan teknologi tersebut. Dengan kemajuan teknologi, inovasi dan efesiensi terus dilakukan untuk menunjang kinerja para pegawai dalam melakukan berbagai hal.

Teknologi yang semakin berkembang mengikuti kebutuhan manusia yang semakin membesar. Demikian pula kebutuhan instansi pemerintah yang dituntut lebih cepat dan efisien dalam melakukan berbagai hal. Salah satu contoh pemanfaatan teknologi di dalam instansi pemerintah adalah pengunaan komputer untuk menunjang kinerja para pegawai.

Dinas Tenaga Kerja dan Transmigrasi (Disnakertrans) D.I.Y adalah salah satu instansi pemerintah yang berperan dalam pengadaan pegawai, pelatihan pegawai sampai mutasi pegawai pemerintah. Dinas Tenaga Kerja dan Transmigrasi merupakan dinas yang mempunyai kedudukan dan fungsi yang sangat penting dalam pemerintahan Republik Indonesia. Oleh karena itu Disnakertrans perlu mengikuti perkembangan teknologi. Disnakertrans telah menyediakan bagian tersendiri dalam mengatasi masalah yang berhubungan dengan teknologi . Bagian tersebut adalah bidang bina program dimana bidang ini masih dibagi menjadi 4 bagian yaitu :

1. Seksi Perencanaan

2. Seksi Promosi dan Pengembangan

3. Seksi Data dan Teknologi Informasi

4. Seksi Monitoring dan Evaluasi

2. RUMUSAN MASALAH 
Untuk menginputkan data pemetaan dan perhitungan pengangguran di propinsi Daerah Istimewa Yogyakarta para pegawai menggunakan software yang masih terhitung manual sehingga mengakibatkan waktu yang lama, dikarenakan belum adanya aplikasi yang mendukung untuk melakukan tugas tersebut. Sehingga fokus Kerja Praktek kami adalah membuat Sistem Informasi pemetaan jumlah pengangguran di propinsi Daerah Istimewa Yogyakarta berbasis web untuk mempermudah pengelolaan data.

\section{RANCANGAN DAN DESAIN}

Perancangan proses disini ada 2 yaitu perancangan ERD dan DFD. Berikut adalah proses perancangan ERD Sistem Informasi Pemetaan Jumlah Pengangguran DIY Dinas Tenaga Kerja dan Transmigrasi.

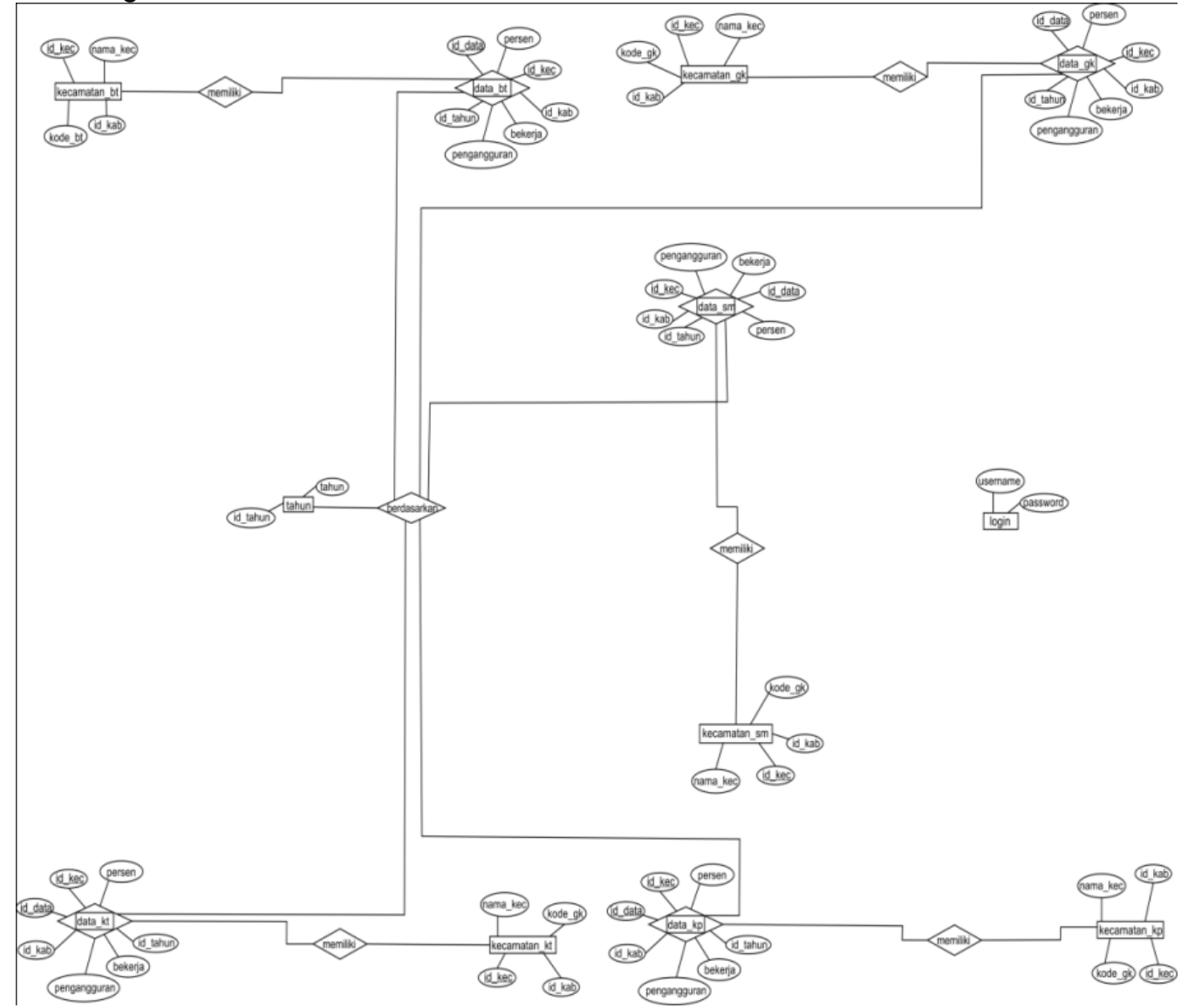

Gambar 1. Entity Relationship Diagram

Proses Perencanaan ERD merupakan salah satu bentuk pemodelan yang menggambarkan kebutuhan informasi dalam Sistem Informasi Pemetaan Jumlah Pengangguran DIY. yang akan disimpan dalam databases tersebut. Sedangkan Proses perencanaan aliran dengan menggunakan Diagram Aliran Data (DAD) / Data Flow Diagram (DFD) sebagai berikuy

\section{Perancangan proses dengan Dara Flow Diagram (DFD)}

DFD atau Data Flow Diagram adalah suatu model untuk menggambarkan asal data, tujuan penyimpanan data, proses yang akan menghasilkan data dan interaksi antara data yang tersimpan dalam proses sistem. Dalam Aplikasi Sistem informasi yang telah kami buat, alur datanya dimulai dari DFD Level 0 atau DCD, DFD Level 1, DFD Level 2, dan seterusnya. 


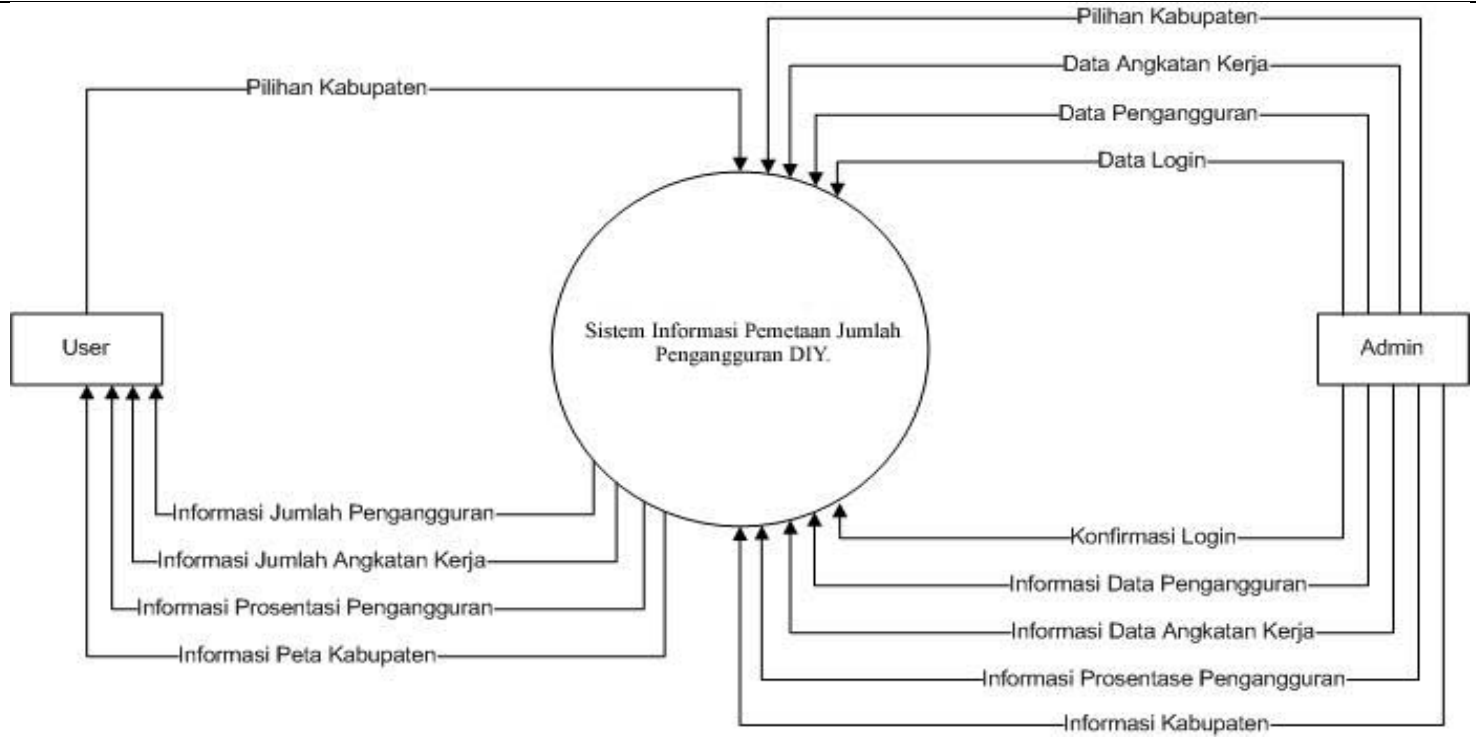

Gambar 2. DFD Level 0

Pada DFD Level 0 ini terdapat dua buah entitas, yaitu entitas User dan entitas Admin, serta terdapat satu buah proses yaitu Sistem informasi pemetaan jumlah penggangguran DIY.. dimana Proses tersebut adalah sebuah sistem dan memiliki subsistem yang terdapat aliran data masuk dan aliran data keluar dari proses tersebut.

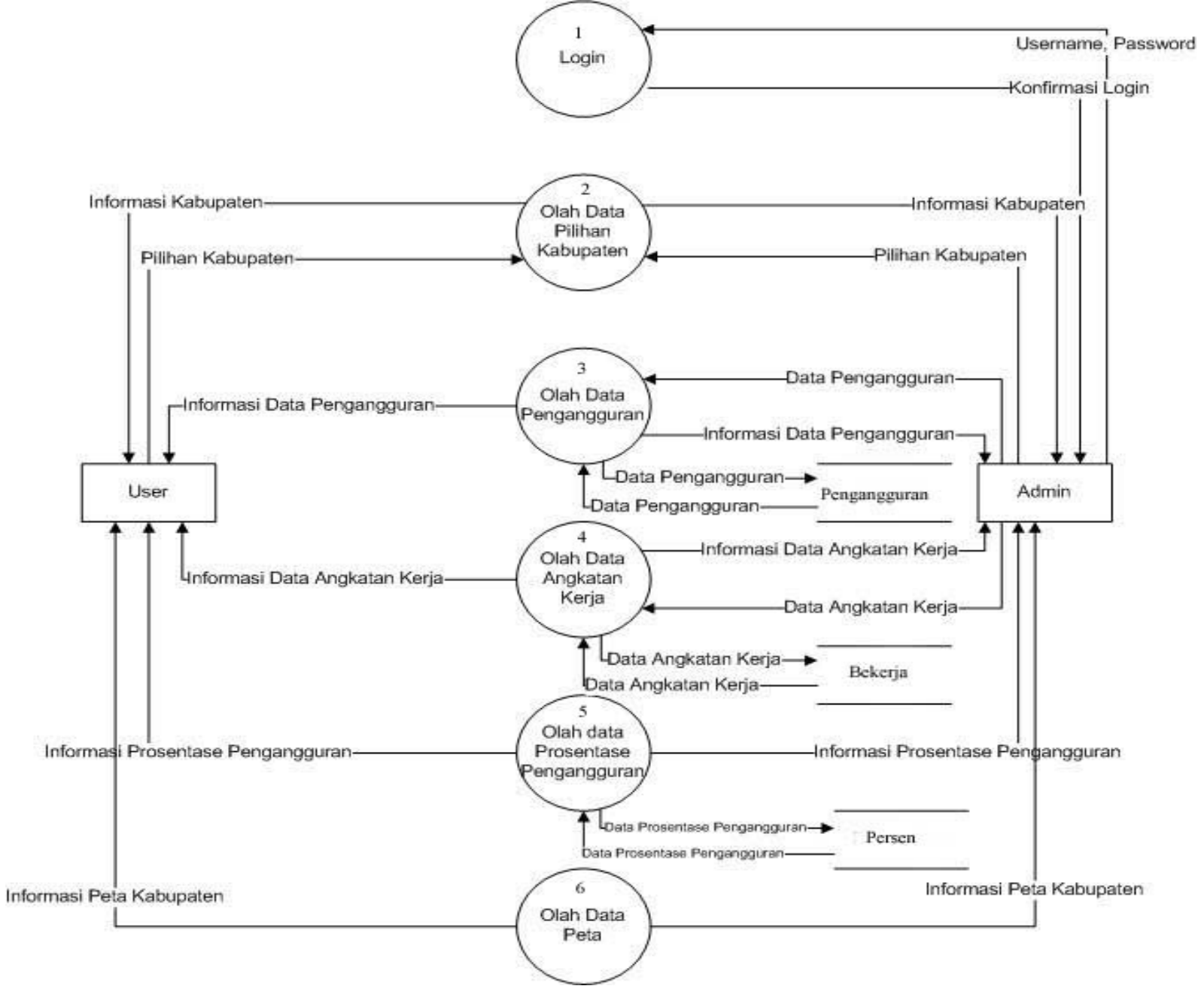


Gambar 3. DFD Level 1

Pada DFD level 1 ini dijelaskan bahwa user tidek perlu login untuk masuk dalam system ini dimana user hanya memilih proses pilihan kabupaten kemudian user akan mendapatkan informasi data pengangguran, data angkatan kerja, data persentase pengangguran dan peta kabupaten.

Kemudian pada DFD level 1 ini dijelaskan bahwa admin harus melalui proses login untuk memasukkan data pengangguran, angkatan kerja sekaligus melakukan pengeditan data tersebut.

\section{Perancangan Struktur Menu}

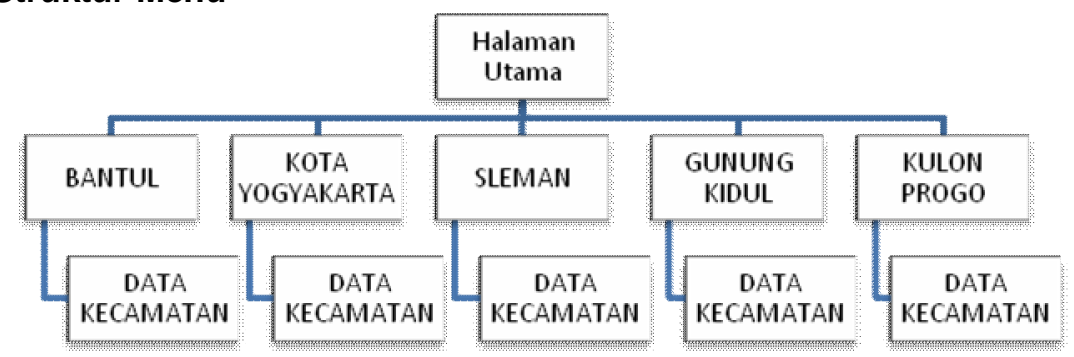

Gambar 4. Struktur menu user

\section{APLIKASI DAN IMPLEMENTASI}

Halaman User adalah halaman pada Sistem Informasi Pemetaan Jumlah Pengangguran Disnakertrans DIY. Didalamnya terdapat halaman utama, halaman login, halaman Kabupaten Bantul, halaman data Kecamatan Bantul, halaman Kabupaten Gunung Kidul, halaman data Kecamatan Gunung Kidul, halaman Kabupaten Kulon Progo, halaman data Kecamatan Kulon Progo, Halaman Kota Yogyakarta, halaman data Kecamatan Kota Yogyakarta, halaman Kabupaten Sleman, dan halaman Kecamatan Sleman.

\section{SISTEM INFORMASI PEMETAAN JUMLAH PENGANGGURAN}

$\overline{\text { HaLAMAN UTAMA }} \overline{\text { BANTUL }} \overline{\text { GUNUNG KIDUL }} \overline{\text { KULON PROGO YOGYAKARTA }} \overline{\text { SLEMAN }}$

\section{Dinas Tenaga Kerja Dan Transmigrasi}

Aplikasi ini dibuat untuk memenuhi syarat Skripsi dan tugas dari Kerja Praktek guna untuk membantu sumber daya dalam pengolahan data pengangguran $\mathrm{di}$ Daerah Istimewa Yogyakarta.

Sistem yang dibuat adalah Sistem Informasi Pemetaan Jumlah Pengangguran di Daerah Istimewa Yogyakarta. Dalam sistem yang dibuat terdapat Peta Yogyakarta yang mempunyai 5 Kabupaten. Kabupaten Bantul, Gunung Kidul, Kota Yogya, Kulon Progo, dan Sleman. Di setiap kabupaten memmiliki beberapa kecamatan yang dimana penduduknya memiliki jumlah penduduk yang berbeda serta masyarakat yang bekerja dan tidak. Tidak hanya untuk mengolah data namun juga untuk mengetahui Presentase Jumlah Pengangguran pada setiap kecamatan yang ada di 5 kabupaten.

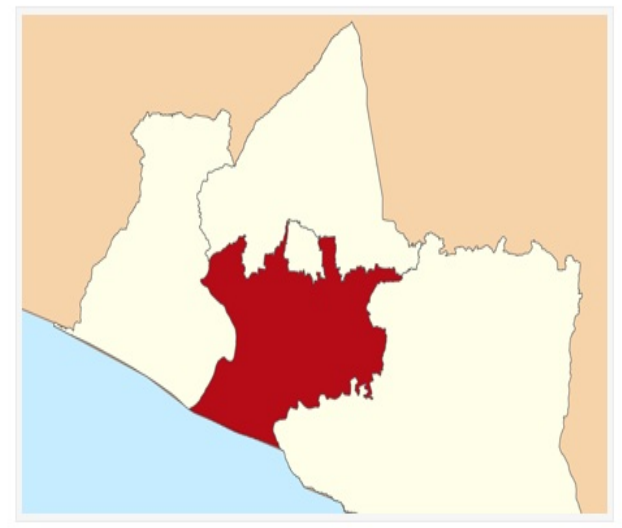


Pada halaman utama terdapat sekilas profil aplikasi dan peta Daerah Istimewa Yogykarta. Di sini terdapat link kelima kabupaten beserta data kecamatanya masing - masing.

SISTEM INFORMASI PEMETAAN JUMLAH PENGANGGURAN

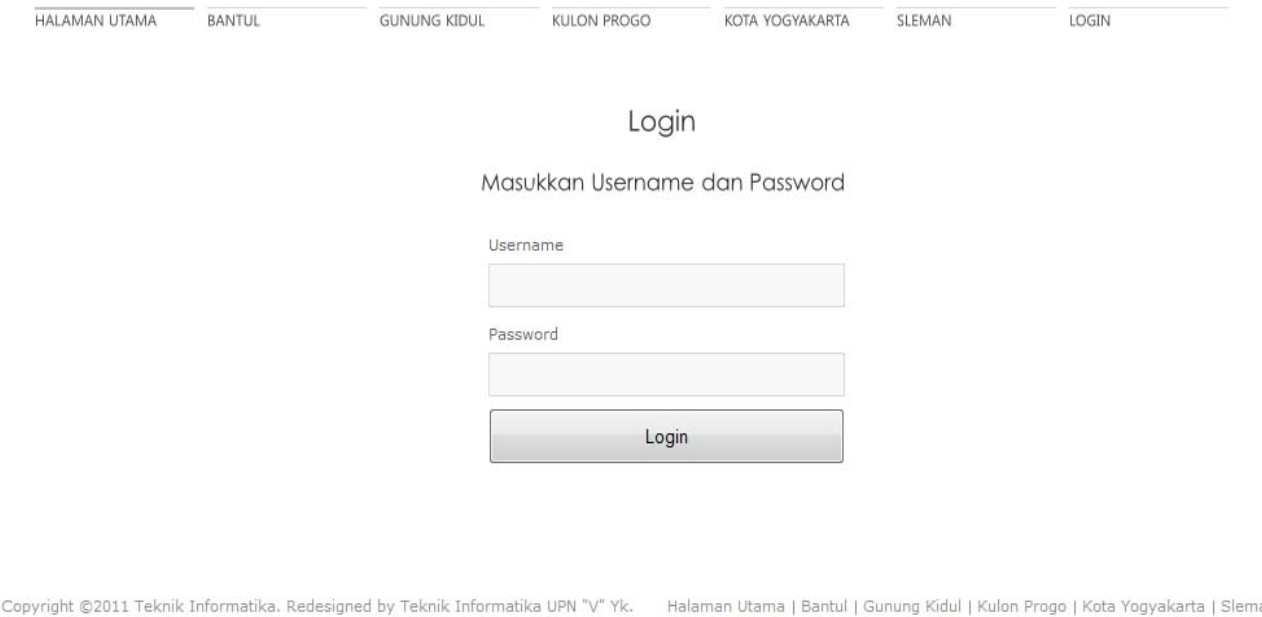

Gambar 6. Halaman Login

SISTEM INFORMASI PEMETAAN JUMLAH PENGANGGURAN

HALAMAN UTAMA BANTUL GUNUNG KIDUL KULON PROGO KOTA YOGYAKARTA SLEMAN IOGIN

Kabupaten Bantul

Pencarian

-Tahun-P Cari

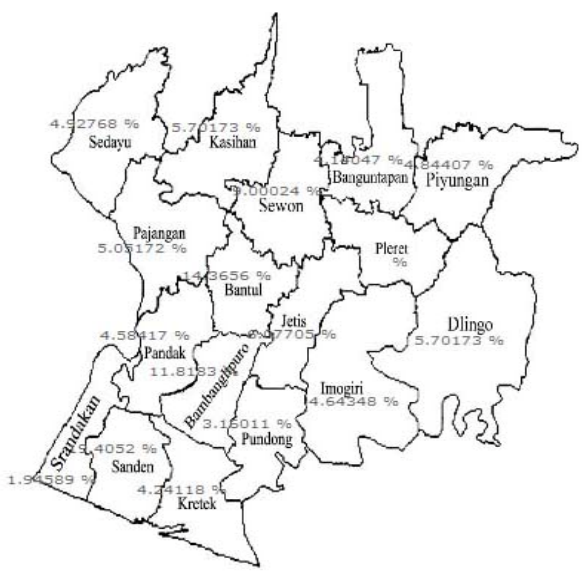

Gambar 7. Halaman Kabupaten Bantul 


\section{SISTEM INFORMASI PEMETAAN JUMLAH PENGANGGURAN}

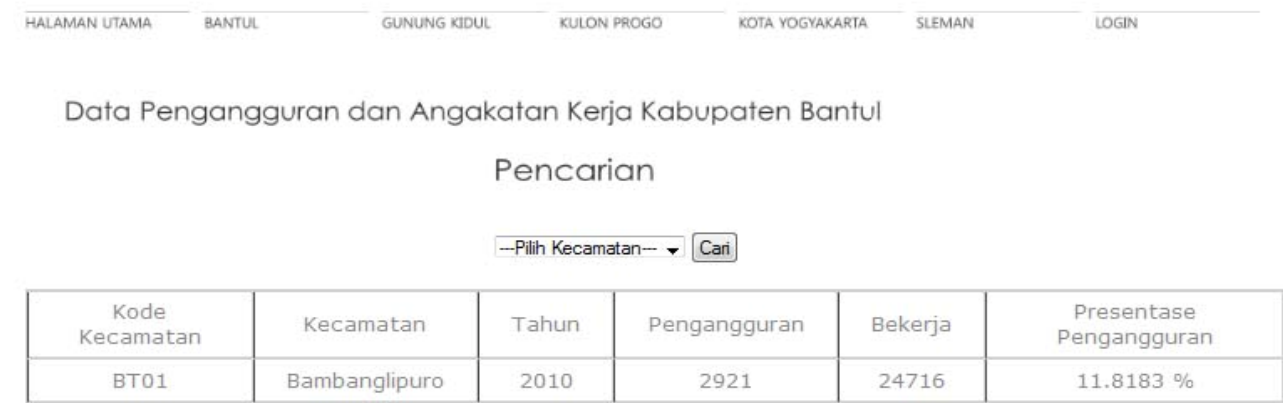

Gambar 8. Halaman Data Kecamatan Bantul

\section{KESIMPULAN DAN SARAN}

Setelah melakukan kerja praktek selama satu bulan ( 2 Oktober - 2 November) di Dinas Tenaga Kerja dan Transmigrasi DIY. Banyak hal yang telah kami dapatkan. Beberapa hal yang dapat disimpulkan setelah menyelesaikan Kerja Praktek adalah :

a. Dengan adanya Sistem linformasi Pemetaan Jumlah Pengangguran Daerah Istimewa Yogyakarta dapat membantu kelancaran pekerjaan para pegawai Dinas Tenaga Kerja dan Transmigrasi Daerah Istimewa Yogyakarta.

b. Sistem Informasi Pemetaan Jumlah Pengangguran dirancang dan diharapkan dapat membantu memudahkan admin untuk menyimpan data dan mengolah data jumlah pengangguran Daerah Istimewa Yogyakarta.

c. Dengan menggunakan teknologi komputer maka kendala - kendala pada penggunaan system manual dapat diatasi dan system keamanan data lebih terjamin.

\section{DAFTAR PUSTAKA}

Kadiman, Kusmayanto. 2006. Penelitian, Pengembangan dan Penerapan IImu Pengetahuan dan Teknologi Bidang Teknologi Informasi dan Komunikasi Tahun 2005-2025. Jakarta: Kementrian Negara Riset dan Teknologi Republik Indonesia.

Polyviou, Zachos A. 2007. The Information Society: Advantages and Disadvantages. Cyprus: University of Wales.

Wijaya, Stevanus Wisnu. 2006. Kajian Teoritis Technology Acceptance Model Sebagai Model Pendekatan Untuk Menentukan Strategi Mendorong Kemauan Pengguna Dalam Menggunakan Teknologi Informasi dan Komunikasi. Prosiding Konferensi Nasional Sistem Informasi. Yogyakarta.

John, 1983 dalam prahasata,2002

Modul Praktikum Pemrograman WEB Jurusan Teknik Informatika Fakultas Teknik Industri Universitas Pembangunan Nasional "Veteran" Yogyakarta 2011.

Modul Praktikum Basis Data Jurusan Teknik Informatika Fakultas Teknik Industri Universitas Pembangunan Nasional "Veteran" Yogyakarta 2011.

http://blog.re.or.id/siklus-informasi.htm

http://id.wikipedia.org/wiki/Server web 